\title{
Leaching Phenomena of Antifouling Agents from Ships' Hull Paints
}

\author{
Ryuji Kojima, Toshiaki Shibata and Koichi Ueda \\ National Maritime Research Institute, 6-38-1, Shinkawa, Mitaka, Tokyo 1810004, Japan
}

\begin{abstract}
The effects of $\mathrm{pH}$, dissolved ion content and relative water velocity on the release rate of an antifouling agent, cuprous oxide, from ships' hull paint have been investigated by rotating cylinder tests. Additionally, test paint panels were attached to a vessel and recovered after a certain period of voyage for the validation of the laboratory tests. In the initial period, the release rates are influenced by $\mathrm{pH}$, dissolved ion content and water velocity, but once after a certain period of test, those effects become less significant. These phenomena can be explained when the paint film is fresh, the rate is controlled by chemical reaction, the surface and/or diffusion layer in the water phase governs the rate. After the antifouling substance in the paint film leached out from the near-surface region, a diffused layer (leached layer), that has little antifouling agent remained, is formed at the surface of the coating, and the diffusion in that layer can be a rate-determining process. The development of the leached layer is affected by a balance between the leaching rate of the antifouling ingredient and paint resin determined by the chemical properties and speed of the water. Thus, the leaching rates of antifouling agents are affected by the history of the paint in the water.
\end{abstract}

Key words: Antifouling agent, leaching rate, cuprous oxide, rotating cylinder, substituted ocean water, phosphate buffer solution.

\section{Introduction}

The deleterious effects from the unwanted accumulation caused by the chemical substances have been much attention as aquatic environmental problems for many years [1]. A significant route of exposure into an environment is entry of antifouling agents into the ocean environment as they are released from paint coatings, and the deleterious effects of the ships' hull paint have been recognised [2]. Therefore, a leaching rate of antifouling agent is a critical parameter for the environmental risk assessment in a calculation of PEC (predicted environmental concentration) values [3]. In order to obtain the PEC values of antifouling agents from ships' hull paints, it is necessary to estimate the leaching rate of antifouling agents from ships particularly when they voyage or berth in a harbour and an inland sea. Therefore, release rates of antifouling ingredients from the coatings of ships' hull are required by a number of regulatory authorises

Corresponding author: Ryuji Kojima, Ph.D., senior researcher, research fields: environmental science, photochemistry. according to ASTM (American Society for Testing and Materials) and the ISO (International Standard Organization) which codify the methods to measure the release rate of an antifouling ingredient into the aquatic environment [4-6].

The test method, however, has not yet been validated to reflect the release rate of antifouling ingredients from coatings. Therefore, it should not be used in the process of conducting environmental risk assessments at present. Furthermore, the test method serves only as a guide for characterization of the early stage of the release as well as estimating the steady state leaching rate of antifouling ingredients from coatings. Further, it is stated in ISO (15181-1) that actual release rate of antifouling ingredients from ships' hull paints into the environment will depend on many factors such as ship operating schedules, length of service, berthing, conditions, paint condition, as well as temperature, salinity, $\mathrm{pH}$, pollutants and bacterial effect $[7,8]$.

The authors have conducted various test methods related the leaching rate of antifouling agents $[9,10]$. As for the rotating cylinder tests, it has been found that 
the release rate is influenced by $\mathrm{pH}$, dissolved ion content and the rotation speed of test cylinder [9]. However, the leaching phenomena of antifouling agents actually occurring in the ocean are considered to be much different from those observed in the laboratory tests $[7,11]$.

In order to investigate the leaching phenomena of the antifouling agents, laboratory and field tests have been carried out to clarify the factors affecting the release rate. In addition, observations of cross-sections of coatings by SEM (scanning electron microscope) were carried out to analyse the leaching mechanisms.

\section{Experiment}

\subsection{Rotating Cylinder Test}

Rotating cylinder tests were conducted complying with ASTM, D 6442 [2]. Test cylinders are made of polycarbonate (Nalugene) of $12 \mathrm{~cm}$ in height, and of approximately $6.4 \mathrm{~cm}$ in diameter, coated with commercially available paints A and B as a band of 10 $\mathrm{cm}$ around the exterior circumference of the test cylinder to provide paint film of $200 \mathrm{~cm}^{2}$. The paint film can be immersed and rotated in the release rate measuring container. Prior to the test, cylinders were once immersed in for 24 hours. The tests were carried out under specified conditions in rotation speed of cylinder, chemicals of testing solution (substituted ocean water: S.O.W., de-ionized water: D.I.W., phosphate buffer solution: P.B.S.), and $\mathrm{pH}$. The test apparatus is shown in Figs. 1 and 2.

After the test, the cylinder was placed in a holding tank which was filled with S.O.W. The temperature and $\mathrm{pH}$ were controlled at $25{ }^{\circ} \mathrm{C}$ and 8.2 , respectively. At a certain period of the holding interval, the cylinder was transferred from the holding tank to individual measuring container. The test solution of $1,500 \mathrm{ml}$ was controlled at a specified temperature and leaching conditions as a similar manner to those mentioned above. The rotation period of the measurement of the release rate is up to 1 hour. After the measurement, the cylinder was placed back to the holding tank, and the alternate process of immersion of holding tank and the measurement of release rate was repeated. In addition, the standard test conditions were settled at a rotating speed of $60 \mathrm{rpm}$ and a temperature of $25{ }^{\circ} \mathrm{C}$ in S.O.W. solution. The release rate was determined by measuring the concentration of copper in the resultant test solution by AAS (atomic absorption spectroscopy).

\subsection{The Coatings}

The tested coatings were commercially available antifouling paints designed as Coating A and Coating B, respectively. The both paints contain cuprous oxide $\left(\mathrm{Cu}_{2} \mathrm{O}\right)$ as a main antifouling agent. The chemical compositions of Coatings A and B are shown in Table 1

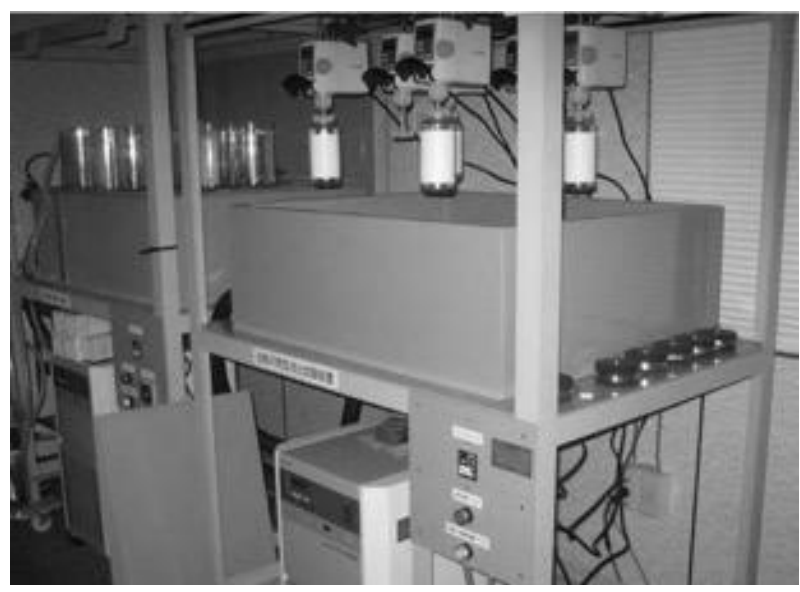

Fig. 1 Photograph of the rotating cylinder test apparatus: The test cylinder holding tank is on the left and the test cylinder measuring tank is on the right.

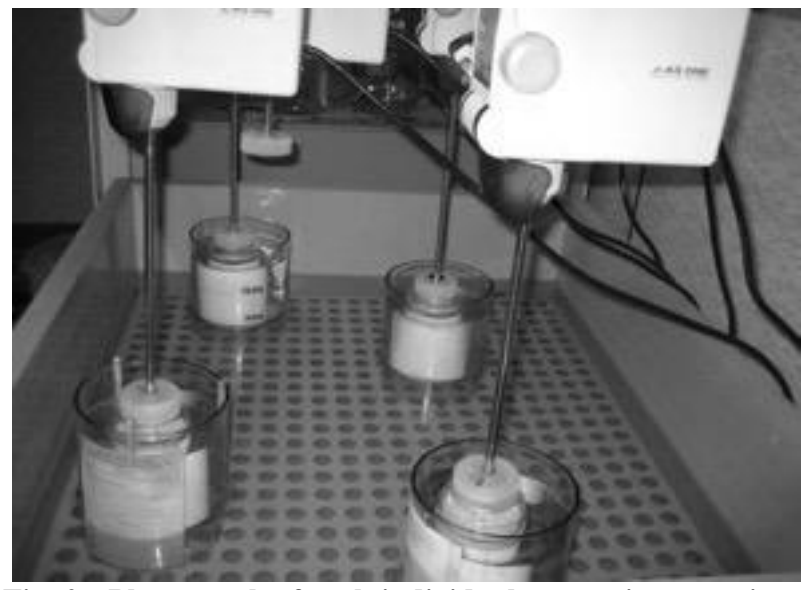

Fig. 2 Photograph of each individual measuring container in the measuring tank. The effects of $\mathrm{pH}$, dissolved ion content or rotation speed of test cylinder on the leaching rate of antifouling agents are investigated at this stage. 
from the MSDS (Material Safety Data Sheet).

\subsection{The Leaching Rate of Test Panels Attached on the Vessel}

In order to investigate the leaching phenomena in actual sea, the release rate of antifouling agent from the test panels attached on a ship's hull was measured. Flat panels were prepared for Coatings A and B painted on steel plates of $500 \mathrm{~mm}$ squares with a thickness of 2 $\mathrm{mm}$. The plates were first sandblasted and then coated with a zinc-rich primer on the surface. Antifouling paints A and B were coated in a similar way as for cylinders. The flat panels of each paint were attached on the center position of bilge keel of the ship, as shown in Fig. 3. The panels were recovered after a voyage for six months. The release rate was calculated as follows; mass concentration of copper in the paint films was analyzed by X-ray fluorescent spectroscopy, as shown in Table 3. The thickness of the paint film was measured by a film thickness meter of electromagnetic detection before and after the test. Mass loss was obtained from the thickness reduction using the specific gravity of the paint film, and then mass of the leached copper was calculated.

\subsection{The Leaching Rate of Static Condition Recovered from Test Panels on the Ship}

Another test was conducted to measure the release rate under a static condition for two types of panels with different situations, that is, non-aged panel (for control) and one after voyage for six months, as shown in Fig. 4.

Before testing, the surface of the latter one was cleaned by tap water. In order to measure the release rate of antifouling agents, the panels were immersed in S.O.W. of $20 \mathrm{~L}$ controlled at $\mathrm{pH} 8.2$ at room temperature, and were settled in a horizontal position with a downward direction for the paint surface facing to S.O.W. directly. The test solution was sampled during a given time of immersion (0 hour and every 1 hour, up to 4 hours), and followed by AAS to analyze

Table 1 The formulation of coating (weight mix, wt\%).

\begin{tabular}{lll}
\hline Formulation & \multicolumn{2}{c}{ Coating } \\
\cline { 2 - 3 } & $\mathrm{A}$ & $\mathrm{B}$ \\
\hline $\mathrm{Cu}_{2} \mathrm{O}$ & $45-50$ & $45-50$ \\
$\mathrm{ZnO}$ & $5-10$ & $5-10$ \\
$\mathrm{Xylene}$ & 8 & 16 \\
Ethylbenzene & 9 & 12 \\
n-Buthylalcohol & $1-5$ & - \\
Propylene glycol & $5-10$ & - \\
Monomethyl ether & - & 5 \\
TiO & & $1-5$ \\
$\mathrm{Copper}_{2}$ & $1-5$ & \\
\hline
\end{tabular}

*These data are derived from MSDS of Chugoku Marine Paint, Ltd.

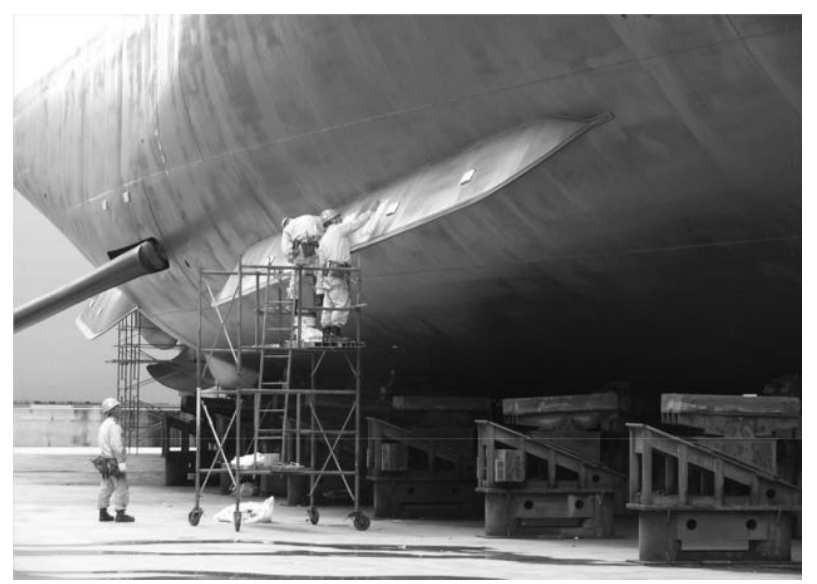

Fig. 3 Photograph of the attachment of test panels at the bilge keel of Seiun-Maru (a training vessels, National Institute for Sea Training).

Table 2 The anticipated effects on leaching rate of antifouling ingredients.

\begin{tabular}{ll}
\hline Effective factors* & \\
\hline Rotation speed & $0,30,60,180$ rpm, respectively \\
Ions & SOW (substitued ocean water), DIW (deionized water), and PBS (phosphate buffer solution)** \\
$\mathrm{pH}$ & 7,8 and 9 (controlled by dil. $\mathrm{HNO}_{3}$ and $\mathrm{NaOH}$ of $0.1 \mathrm{~N}$ ) \\
History records & rotation speed, ions and $\mathrm{pH}$ of immersion $* * *$ \\
\hline
\end{tabular}

\footnotetext{
* The test solution was prepared at $\mathrm{pH} 8.2$ exception of $\mathrm{pH}$ experiment;

** PBS was prepared by $\mathrm{KH}_{2} \mathrm{PO}_{4}-\mathrm{Na}_{2} \mathrm{HPO}_{4}$;

*** Test cylinders were conducted each case of leaching test up to 24 hours in advance, respectively.
} 
Table 3 Elemental analysis of paints in the experiment.

\begin{tabular}{lll}
\hline \multirow{2}{*}{ Eletments } & \multicolumn{2}{c}{ Paint (mass\%) } \\
\cline { 2 - 3 } & $\mathrm{A}$ & $\mathrm{B}$ \\
\hline $\mathrm{B}$ & 2.27 & - \\
$\mathrm{C}$ & 34.12 & 30.28 \\
$\mathrm{O}$ & 25.08 & 25.34 \\
$\mathrm{Mg}$ & 1.42 & 1.18 \\
$\mathrm{Al}$ & 0.17 & 0.14 \\
$\mathrm{Si}$ & 1.08 & 2.78 \\
$\mathrm{P}$ & 0.01 & 0.01 \\
$\mathrm{~S}$ & 0.84 & 0.58 \\
$\mathrm{Cl}$ & 1.36 & 0.23 \\
$\mathrm{Ca}$ & 0.03 & 0.35 \\
$\mathrm{Fe}$ & 0.40 & 0.35 \\
$\mathrm{Ni}$ & 0.02 & - \\
$\mathrm{Cu}$ & 27.75 & 34.96 \\
$\mathrm{Zn}$ & 5.39 & 3.82 \\
$\mathrm{As}$ & 0.02 & - \\
$\mathrm{Sn}$ & 0.06 & - \\
\hline
\end{tabular}

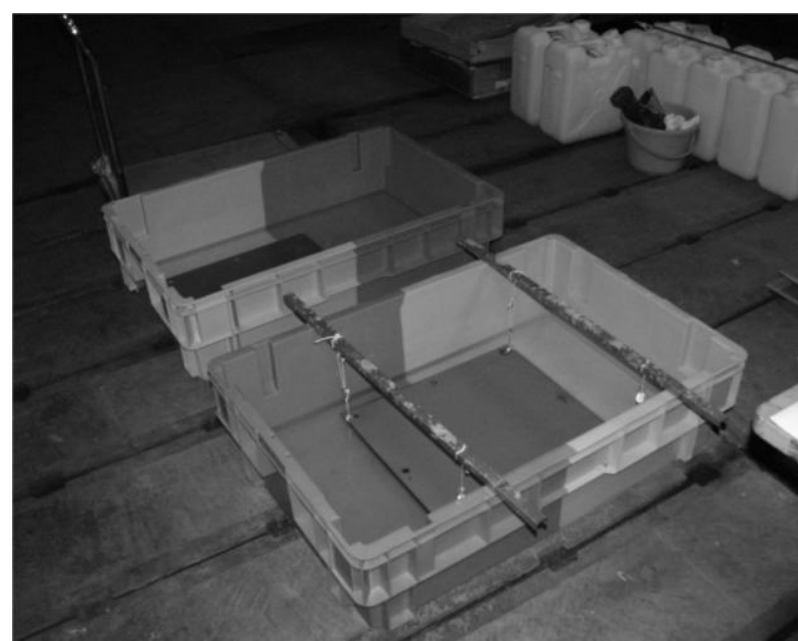

Fig. 4 Photograph of the instrument of the leaching rate of static condition recovered from test panels on the ship.

the concentration of copper. Immersions were conducted up to 10 days, under specified conditions by exchange S.O.W. every day.

\subsection{The Observation of Cross-Sectional Surface of Test Cylinder by SEM}

The test specimens were observed by SEM, as shown in Fig. 5. After the measurement of release rate for 45 days, the test cylinders were sawed across the paint film to give specimens. The specimens were moulded in resin, and polished. The polished cross-sections were observed by SEM in a back-scattered electron image mode.

\section{Results}

\subsection{The Effects of Rotation Speed of Test Cylinder on the Leaching Rate of Antifouling Agents}

The effects of rotation speed of test cylinder varying from $0 \mathrm{rpm}$ to $180 \mathrm{rpm}$ on the release rate are shown in Figs. 6 and 7, where the variation of the release rate of copper was illustrated as a function of the immersion time. For both coatings, the leaching rate of copper increased gradually with an increase in rotation speed of cylinder in an early stage of immersion up to 25 days. In the case of $180 \mathrm{rpm}$ for both coatings, release rates are almost 4 times higher than those in case of $0 \mathrm{rpm}$. It should be noted that even in the $0 \mathrm{rpm}$, copper was released gradually. However, the release rate of copper

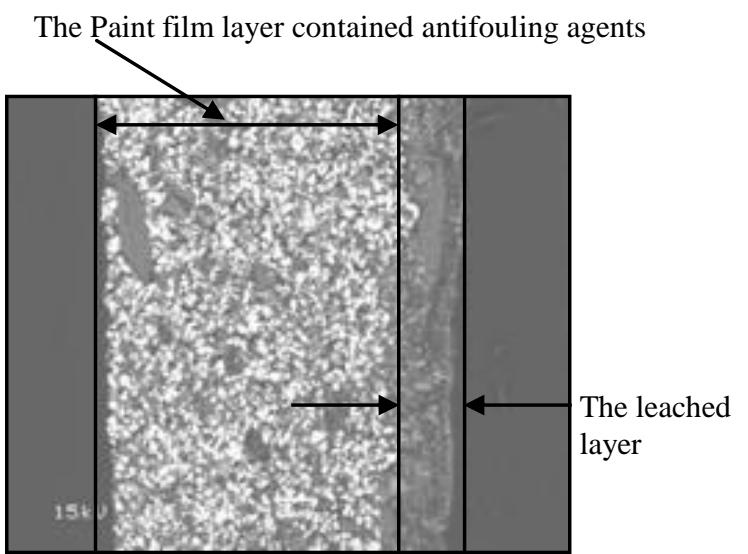

Fig. 5 The back-scattered electron image mode by SEM at 1,000-fold magnification. White colored image shows the antifouling agents as cuprous oxide.

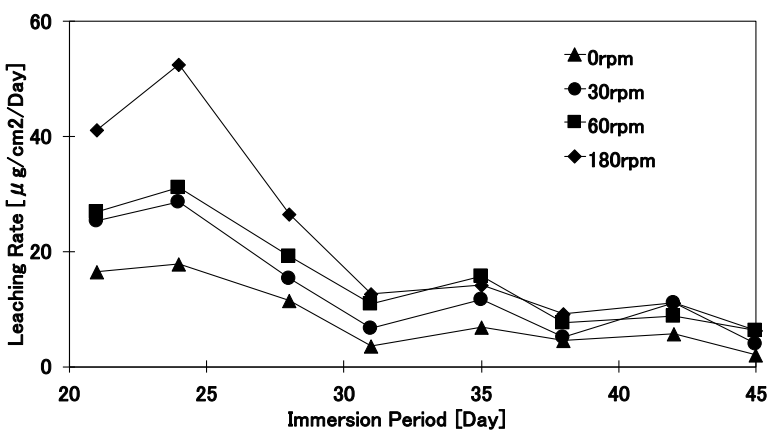

Fig. 6 The variation in the leaching rate of coating $A$ as a function of immersion period of test cylinder up to 45 days. 


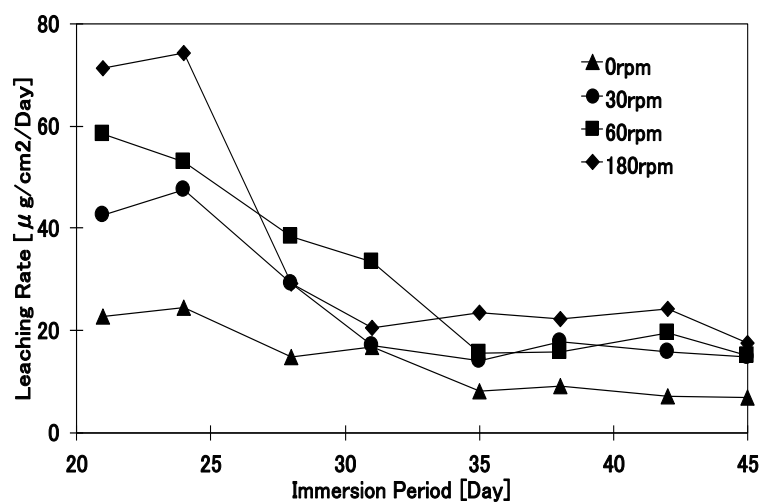

Fig. 7 The variation in the leaching rate of coating $B$ as a function of immersion period of test cylinder up to 45 days.

gradually decreased during the immersion after 30 days, where it still remained being affected by the rotation speed of cylinder [12].

\subsection{The Effects of $p H$ and Dissolved Ion Species on the Release Rate of Antifouling Agents}

The effects of $\mathrm{pH}$ and dissolved ion species on the release rate of copper at a rotation speed of $60 \mathrm{rpm}$ are shown in Figs. 8 and 9 for Coatings $\mathrm{A}$ and $\mathrm{B}$, respectively. These figures show the variation in the release rate of copper as a function of the immersion time. In the both coatings, low $\mathrm{pH}$ (at $\mathrm{pH}$ 7) showed a great influence on the leaching rate of copper at the initial stage of immersion period (the first day). It showed almost 10 times higher than other factors with an exception of the case in P.B.S of coating A. However, the release rate of copper decreased significantly at the third day and gradually decreased during the immersion test. The release rate of copper for both coatings showed similar values at a later period of test, e.g., at 28 days, independent of $\mathrm{pH}$ and dissolved ion content.

\subsection{Comparison of Release Rate between Laboratory} Test (Rotating Cylinder Test) and Field Test (Flat Panel Test)

The distance of voyage and temperature are shown in Fig. 10 [10, 13]. Generally, the thickness of film decreased more for a longer period of voyage, and the decrease rate of film thickness depended on both the

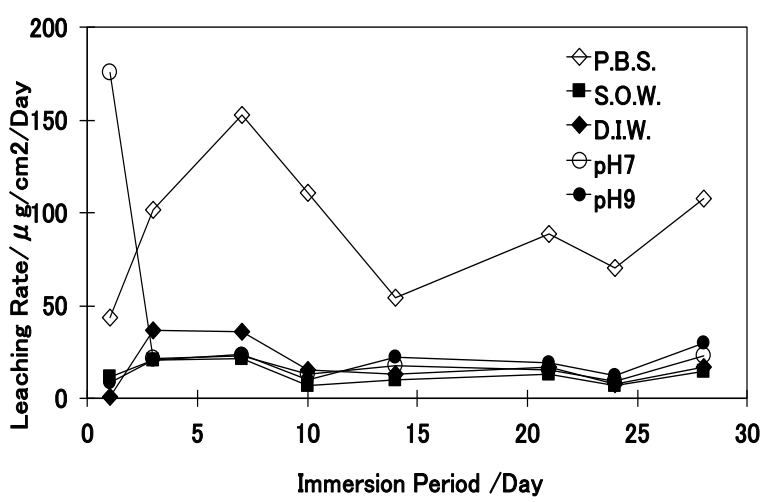

Fig. 8 The variation in the leaching rate of coating $A$ as a function of immersion period of test cylinder up to 28 days.

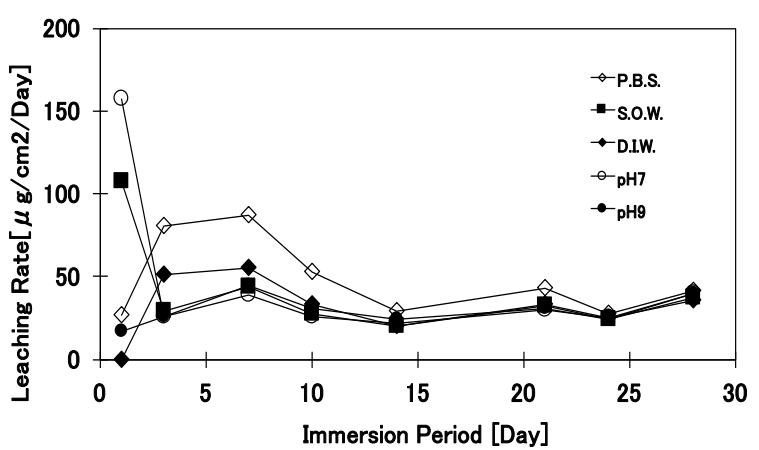

Fig. 9 The variation in the leaching rate of coating $B$ as a function of immersion period of test cylinder up to 28 days.

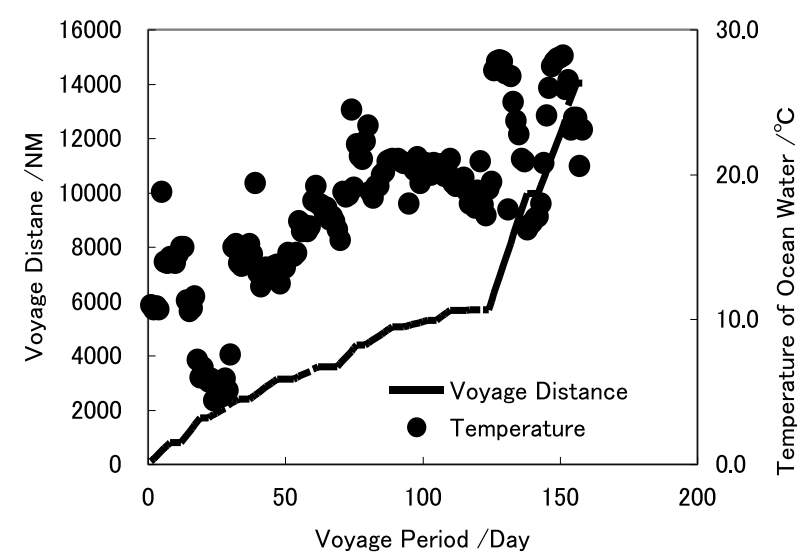

Fig. 10 Profiles of voyage distance and temperature of ocean water of Seiun-Maru in 2007 [10, 13].

average speed of the ship and the temperature of ocean water.

The comparison of the release rate with or without water flow rate between the rotating cylinder test $(60$ rpm; flow rate, $0.4 \mathrm{~m} / \mathrm{s}$ ) and the field test was shown in Figs. 11 and 12, respectively. The authors obtained some results are summarized as follows: 


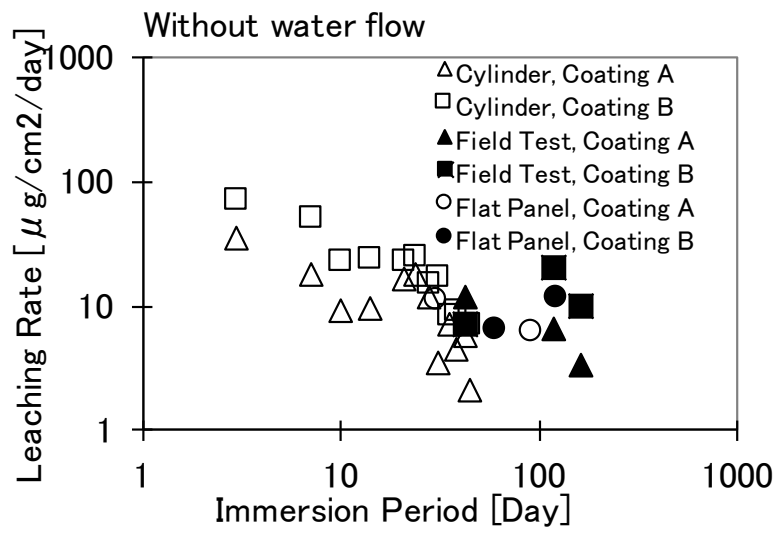

Fig. 11 The comparison of the leaching rate without water flow between rotating cylinder test, field test of flat panel and laboratory test of flat panel recovered from field test [10].

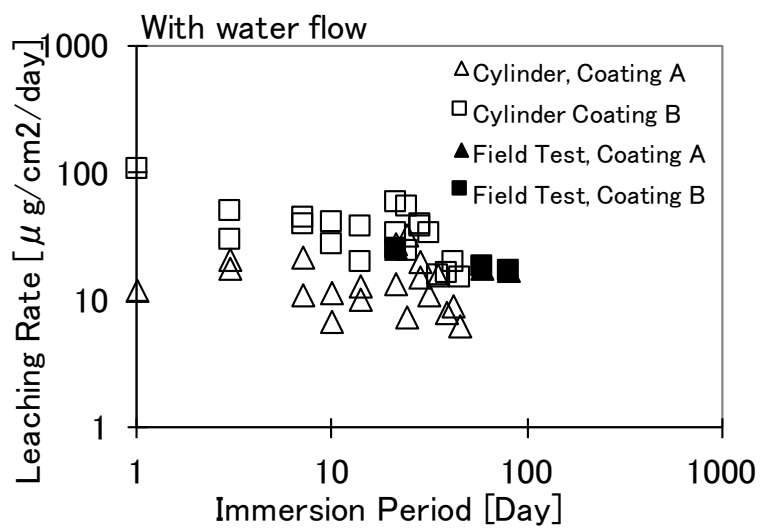

Fig. 12 The comparison of the leaching rate with water flow between rotating cylinder test and field test of flat panel [10].

- The release rate of copper decreases with increasing test period.

- The release rates of antifouling ingredient from Coatings A and B are affected by flow rate of water.

- The release rate of antifouling ingredient of Coating $\mathrm{B}$ is much higher than that of Coating A.

- The release rate obtained by the cylinder test is almost equivalent to the field test when the test period of cylinder test is long.

\subsection{The Mechanism of Leaching of Antifouling Agents}

3.4.1 The Observation of the Cross-Section of Specimens by SEM

The cross-sections of specimens were observed by
SEM. Figs. 13 to 16 show the cross-sectional images of paint films after the leaching tests. In each coating, except for the case of Coating A in P.B.S., a leached layer, where cuprous oxide particles were not present, was observed at the surface of the coating. Thicknesses of the layers with and without copper content were measured on these images. These results are summarized in Table 4.

3.4.2 The Mechanism of Leaching Rate of Antifouling Agents

In the case of rotating cylinder tests, these phenomena can be explained as follows; in the initial stage of leaching, the release rate of antifouling agents is affected both by the resistance of diffusion in the laminar film and by dissolution of antifouling agents at the interface between the coating and water.

When the copper near the surface has been leached out, remaining polymer forms a skeleton structure as shown in Fig. 13. In this stage, cuprous oxide reacts with water, diffuses within the surface layer and is released into seawater. The above scenario suggests that leaching process changes from the surface reaction in the initial stage to the diffusion within the leached layer in the later stages where diffusion within the leached layer, rather than the chemical reaction between the cuprous oxide and seawater, should control the release rate.

Whereas, in the case of Coating A in P.B.S, as shown in Fig. 15a, the leaching phenomena of antifouling agents were quite different from others. Because the leached layer was not formed in that case, the surface was always affected by the surrounding of water, like fresh paint as mentioned above. The development of leached layer into the coating is affected by balancing between the leaching rate of antifouling agents and resin copolymer of coating determined by the physical and chemical properties of water phase. Similar manner of these phenomena could occur in the case of field tests of flat panel. 
Table 4 Parameters of the cross-section of specimens.

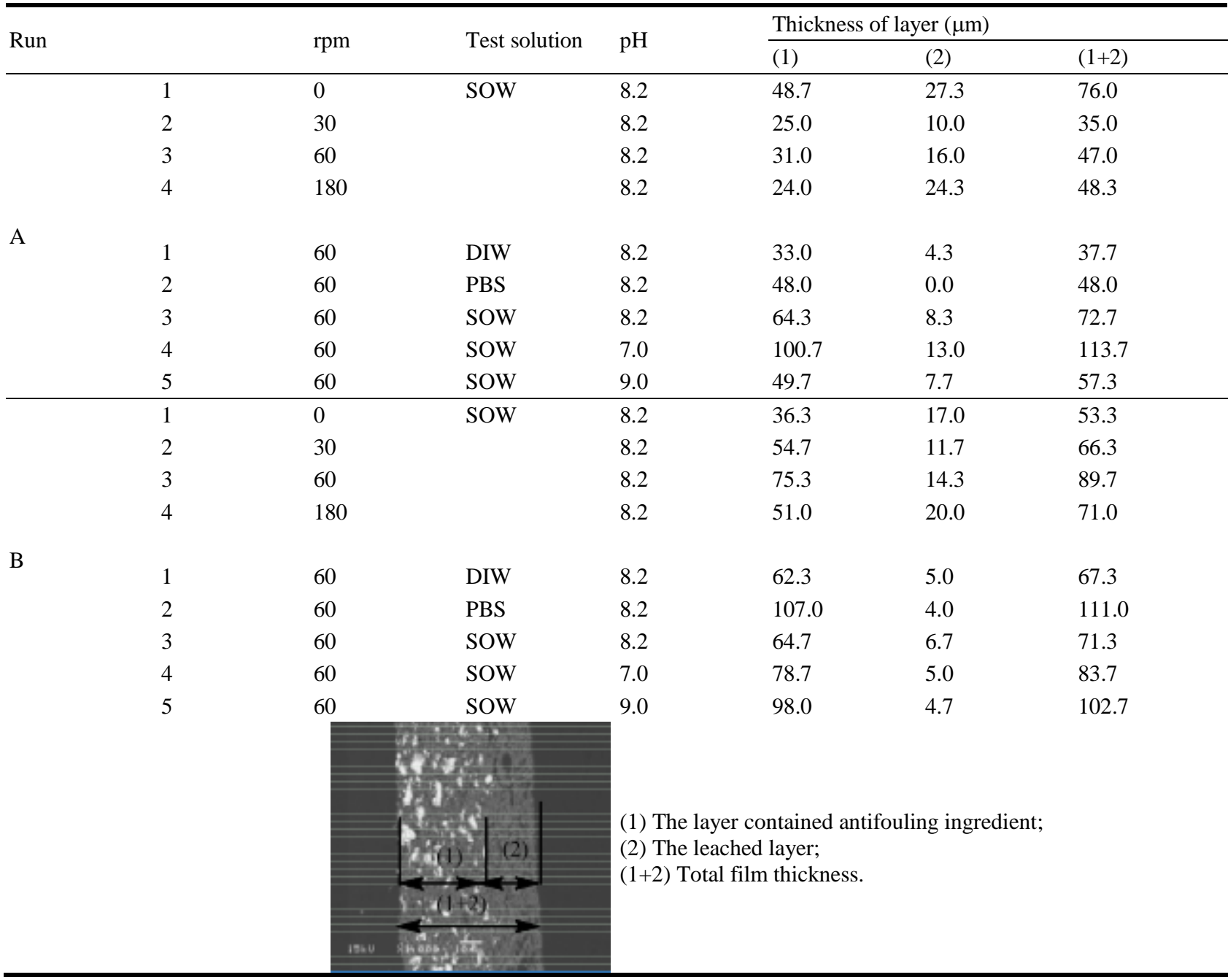

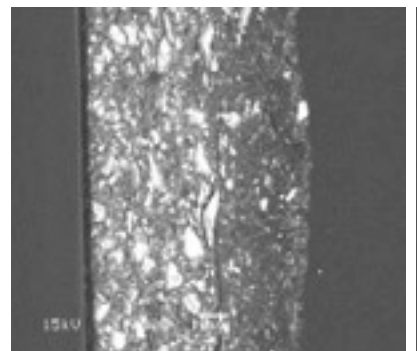

(a) $0 \mathrm{rpm}$

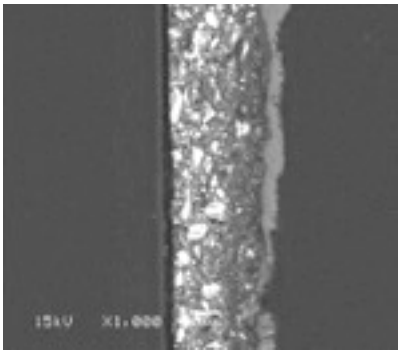

(b) $30 \mathrm{rpm}$

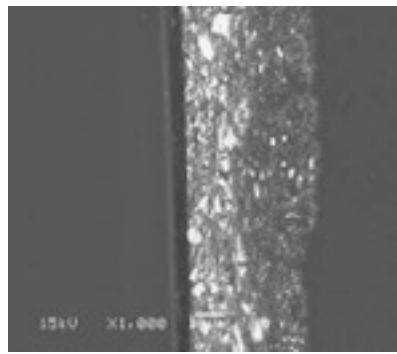

(c) $60 \mathrm{rpm}$

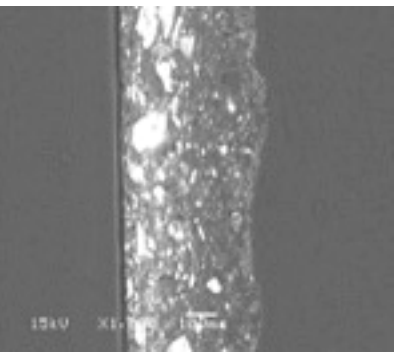

(d) $180 \mathrm{rpm}$

Fig. 13 The images of cross-sectional surface of cylinders in the case of coating A verified with the rotation speed of cylinders at the rate from: (a) $0 \mathrm{rpm}$; (b) $30 \mathrm{rpm}$; (c) $60 \mathrm{rpm}$ and (d) $180 \mathrm{rpm}$ after immersion of the holding tank for $45 \mathrm{days}$, respectively. 


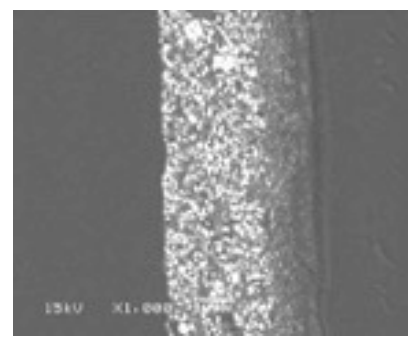

(a) $0 \mathrm{rpm}$

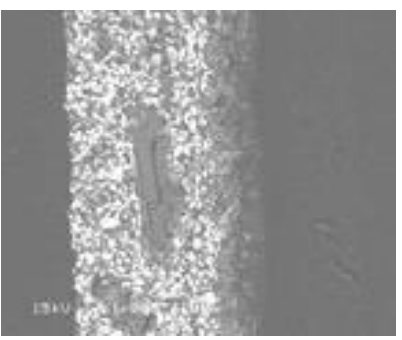

(b) $30 \mathrm{rpm}$

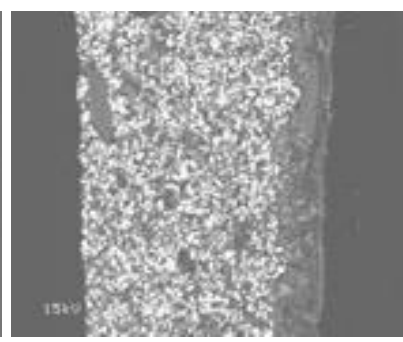

(c) $60 \mathrm{rpm}$

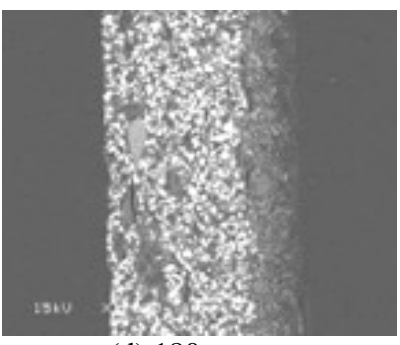

(d) $180 \mathrm{rpm}$

Fig. 14 The images of cross-sectional surface of cylinders in the case of coating $B$ verified with the rotation speed of cylinders at the rate from: (a) $0 \mathrm{rpm}$; (b) $30 \mathrm{rpm}$; (c) $60 \mathrm{rpm}$ and (d) $180 \mathrm{rpm}$ after immersion of the holding tank for 45 days, respectively.

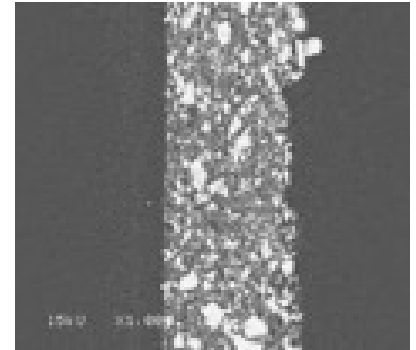

(a) P.B.S

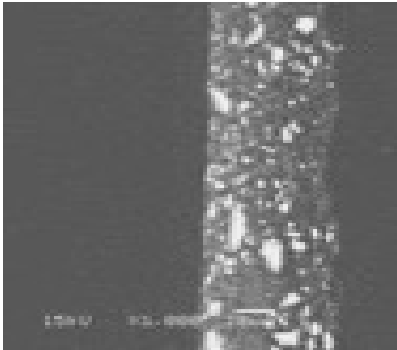

(b) D.I.W .

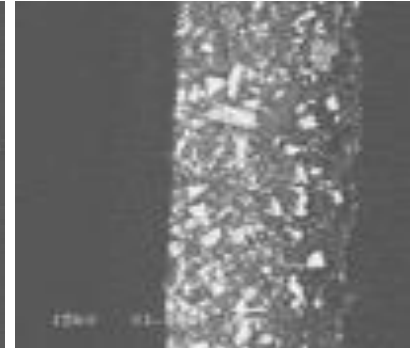

(c) $\mathrm{pH} 9$

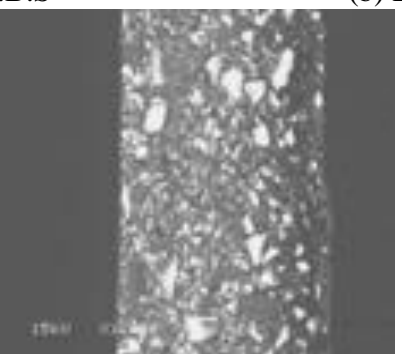

(d) S.O.W

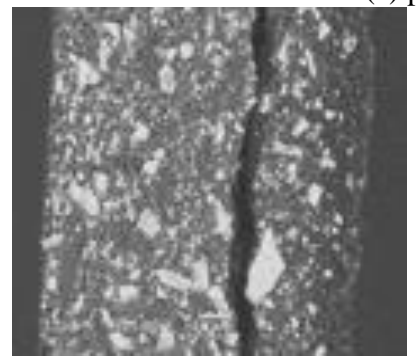

(e) $\mathrm{pH} 7$

Fig. 15 The images of cross-sectional surface of cylinders in the case of coating A verified with the chemical property of water phase: (a) P.B.S.; (b) D.I.W.; (c, as control), pH 9; (d) S.O.W. and (e) pH 7 after immersion of the holding tank for 28 days, respectively.

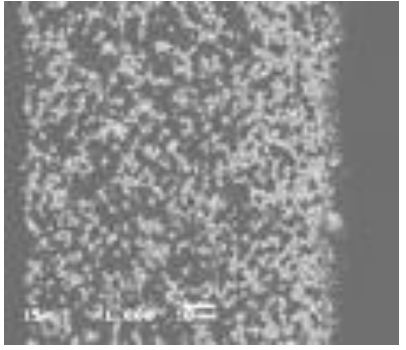

(a) P.B.S

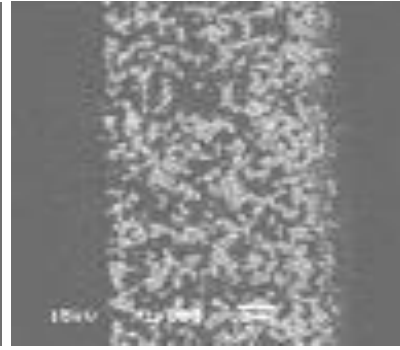

(b) D.I.W.

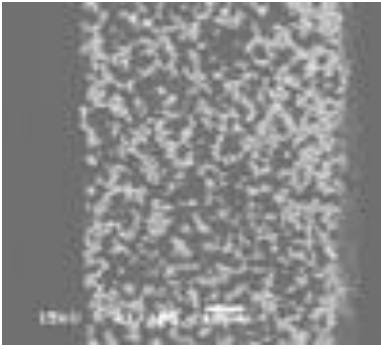

(c) $\mathrm{pH} 9$

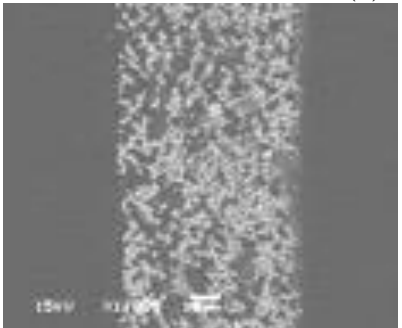

(d) S.O.W

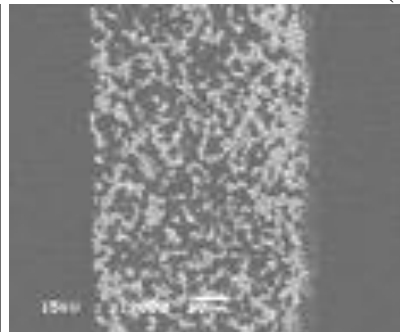

(e) $\mathrm{pH} 7$

Fig. 16 The images of cross-sectional surface of cylinders in the case of coating $B$ verified with the chemical property of water phase: (a) P.B.S.; (b) D.I.W.; (c, as control), pH 9; (d) S.O.W. and (e) pH 7 after immersion of the holding tank for 28 days, respectively. 


\section{Conclusion}

The authors investigated the effects of chemical and physical properties of water phase by various tests. The conclusion can be summarized as follows:

At the initial period in the rotating cylinder tests, the leaching rates are influenced by $\mathrm{pH}$, dissolved ion content and water velocity, but after a certain period of leaching, those effects become smaller.

It is necessary to control the chemical and physical condition of the aging tank during the aging period of test in which the leached layer was developed.

In the field tests, the leaching rate of copper decreases with increasing test period, and the leaching rates of antifouling agents from Coatings $\mathrm{A}$ and $\mathrm{B}$ are affected by flow rate of water.

These differences can be largely ascribed to the different hydrodynamic conditions of exposure; the immersed panels have been subjected only to tidal flow, whereas the vessels have alternated between periods under tidal flow at pier-side and active in-service periods at the vessel's operating speed.

The release rate of the cylinder test could be almost equivalent to that of this field test, as the leaching period became long.

It is recognized that this investigation may be confined to matters on this experiment of data for copper release rate.

The different phenomena of leaching rate of antifouling agents can be explained by the development of the leached layer, which formed near the surface of coating.

The historical record of the coating in aquatic condition affects the leaching rate of antifouling agents.

\section{Acknowledgements}

The authors would like to express their gratitude to Chugoku Marine Paints, Ltd., for preparation of flat panels and cylinders for tests. The authors are also grateful thank to Mr. Kaneto Watanabe of National Institute for Sea Training for the field test by Seiun
Maru. This study was conducted under the financial support by the Ministry of the Environment of Japan. This was also funded under research project of Ministry of Land, Infrastructure and Transport of Japan.

\section{References}

[1] Allen, H. E., and Hansen, D. J. 1996. "The Importance of Trace Metal Speciation to Water Quality Criteria." Water Environ. Res. 68: 42-54.

[2] Anon. 1952. "Marine Fouling and Its Prevention." Annapolis: Woods Hole Oceanographic Institute, 388.

[3] European Commission. 2003. "Technical Guidance Document on Risk Assessment in Support of Commission Directive 93/67/EEC on Risk Assessment for New Notified Substances." Available from http://ecb.jrc.it/Technical-Guidance_Document.

[4] ASTM. 2005. "Standard Test Method for Determination of Copper Release Rate from Antifouling Coatings in Substitute Ocean Water." ASTM Method D 6442 (5): 9.

[5] ISO. 2000. "Determination of the Release Rate of Biocides from Antifouling Paints-Part 1: General Method for Extraction of Biocides." International Standard ISO 15181-1.

[6] ISO. 2000. "Determination of the Release Rate of Biocides from Antifouling Paints-Part 2: Determination of Copper-Ion Concentration in the Extract and Calculation of the Release Rate." International Standard ISO 15181-2.

[7] Finnie, A. A. 2006. "Improved Estimates of Environmental Copper Release Rates from Antifouling Products." Biofouling 22: 279-91.

[8] Valkirs, A. O., Seligman, P. F., Haslbeck, E., and Caso, J. S. 2003. "Measurement of Copper Release Rates from Antifouling Paint under Laboratory and in situ Conditions: Implications for Loading Estimation to Marine Water Bodies." Marine Pollution Bulletin 46: 763-79.

[9] Kojima, R., Shibata, T., Miyata, O., Shibata, K., and Senda, T. 2009. "Fundamental Leaching Behaviour on Antifouling Agents from Ships' Hull Paints." Marine Engineering. 44: 648-52. doi: 10.5988/jime.44.648.

[10] Miyata, O., Sugasawa, S., Kojima, R., Shibata, T., Senda, T., Shibata, K., and Watanabe, K. 2009. "Release Rate Measurement of Antifaulant from Hull Paint of Ship." Marine Engineering 44: 292-7. doi: 10.5988/jime.44.292.

[11] Hunter, J. E. 2004. "Regulation and Registration of Anti-fouling Coatings in the European Union." Proceedings of International Symposium on Antifouling Paint and Marine Environment (InSAfE), 11.

[12] Kojima, R. et al. 2007. "The Leaching Behavior of the Antifouling Agent by Rotating Cylinder Method." 
In Proceedings of the 76th Annual Conference of the Japan Institution of Marine Engineering, 19. (in Japanese)

[13] Miyata, et al. 2007. "Verification Antifouling Paint
Leaching Rate Measurement between a Laboratory and on Operating Ship." In Proceedings of the 76th Annual Conference of the Japan Institution of Marine Engineering, 21. (in Japanese) 